\title{
Erratum to: Antifreeze glycopeptides: from structure and activity studies to current approaches in chemical synthesis
}

\author{
Małgorzata Urbańczyk $^{1} \cdot$ Jerzy Góra $^{1} \cdot$ Rafał Latajka $^{1} \cdot$ Norbert Sewald $^{2}$ (I)
}

Published online: 28 January 2017

(C) Springer-Verlag Wien 2017

\section{Erratum to: Amino Acids \\ DOI 10.1007/s00726-016-2368-z}

In the original publication, the below mentioned statement in paragraph 1 of section 'Mechanism of action', was wrongly published. The correct statement should read as:

'The observed difference between the melting and freezing points is referred to as thermal hysteresis (Fig. 2), as depicted in the review by Davies (2014).'

The following publication by Davies should be accordingly added to the reference section:

Davies PL (2014) Ice-binding proteins: a remarkable diversity of structures for stopping and starting ice growth. Trends Biochem Sci 39:548-555.

The online version of the original article can be found under doi:10.1007/s00726-016-2368-z.

Rafał Latajka

rafal.latajka@pwr.edu.pl

$\triangle$ Norbert Sewald

norbert.sewald@uni-bielefeld.de

1 Department of Organic and Pharmaceutical Technology, Faculty of Chemistry, Wrocław University of Science and Technology, Wybrzeże St. Wyspiańskiego 29, 50-370 Wrocław, Poland

2 Organic Chemistry III, Department of Chemistry, Bielefeld University, Universitätsstrasse 25, 33615 Bielefeld, Germany 